\title{
A RELAÇÃO ENTRE ESPAÇO GEOGRÁFICO E O SURGIMENTO DE INOVAÇỐES TECNOLÓGICAS : O CASO DAS EMPRESAS LATI- NO-AMERICANAS DE GRANDE PORTE.
}

\author{
Paulo Roberto Feldmann*
}

\section{RESUMO:}

O texto mostra que o atraso tecnológico da América Latina ocorre devido às suas condições geográficas, que não contribuem para criar um contexto favorável ao surgimento de inovações, principalmente junto às grandes empresas da região. $O$ artigo trata da relação entre as condições geográficas de uma determinada região e o surgimento de inovações, com o objetivo de analisar possíveis causas para o atraso da América Latina nas questões referentes ao desenvolvimento tecnológico. O texto aborda o problema tendo em vista as maiores empresas da região discutindo qual a explicação para o fato destas raramente estarem nos setores classificados como de alta tecnologia. Para buscar essa explicação, o artigo percorre vários autores que se debruçaram sobre o tema detendo-se, principalmente, naqueles que estabelecem comparações com outras regiões do globo, mormente os países asiáticos, tendo em vista caracterizar os aspectos geográficos decisivos para a ocorrência de inovações. O resultado é altamente preocupante, pois são raras as empresas da América Latina que conseguem projeção mundial, e as mesmas quase sempre fazem parte de setores da economia cujo o conteúdo tecnológico muito baixo.

\section{PALAVRAS-CHAVE:}

Inovação, América Latina, Ambiente Empresarial, Atraso Tecnológico

\section{ABSTRACT:}

The paper shows that the technology "gap" faced by Latin America is due to its geographical circumstances, which do not contribute to create a favorable environment in terms of innovation , mostly with respect to the large enterprises of the region. The paper deals with the relation between geographical conditions in a specific region and the occurrence of innovations. The objective is to analyze the reasons for the backwardness of Latin America in matters related to technology development. The article's approach is to observe the largest companies of the region, trying to understand why they almost never are part of the high technology industries. In order to get these explanations, the article mentions many authors that have dedicated themselves to this subject, paying more attention to those who had made comparisons with other regions in the world, specially Asia. The aim here was to characterize the geographic circumstances that were decisive to the ocurrence of innovations. The results are deeply alarming not only because of the low number of latin american companies that have reached worldwide recognition, but also because, almost always, these few companies came from where the technology content is very low.

\section{KEY-WORDS:}

Geography, Innovation, Latin America, Business Environment, Technological Delay 
A importância do efeito da tecnologia no desempenho e na competitividade das empresas é indiscutível: atualmente novos produtos e processos dão às empresas a possibilidade de compensar seus fatores escassos ou fraquezas. E esses novos produtos e processos são obtidos através da tecnologia. Se repararmos na competição existente na maioria dos setores da economia, notaremos que as empresas que são bem sucedidas são as que conseguem usar bem as novas tecnologias, e, de preferência, antes que seus concorrentes o façam.

A tecnologia diminuiu muito a importância dos antigos fatores de produção considerados fundamentais. As vantagens clássicas, como salários baixos, matérias primas abundantes, capital barato ou os grandes mercados internos foram completamente anulados pela competição global que hoje prevalece entre as nações. O novo paradigma da competição é baseado na capacidade dos países e de suas respectivas empresas de inovarem. No entanto, como pretendemos mostrar, as empresas latino-americanas investem muito pouco em pesquisa \& desenvolvimento e raramente atuam nos setores denominados de alta tecnologia. Governos têm responsabilidade neste fato, por não contribuírem para criar um ambiente empresarial apropriado para o surgimento de inovações. Mas talvez a principal causa para esta inapetência tecnológica esteja na própria geografia da região. O presente artigo pretende examinar justamente esta relação entre o espaço latino americano e a ocorrência de inovações tecnológicas.

\section{I- A importância das condições geográficas no surgimento de inovações tecnológicas}

O que torna alguns lugares do mundo mais propensos à inovação do que outros? David Landes (1998) pergunta por que a Revolução Industrial aconteceu na Europa e mais especificamente na Grã Bretanha, e não em outros países. O próprio Landes responde com razões de ordem cultural, histórica e geográfica, mas enfatiza que na Grã Bretanha de meados do século XIX havia uma crescente autonomia da investigação intelectual combinada com um enorme interesse acerca do que na época se chamava "a invenção da invenção", e que Landes denomina de rotinização da invenção. Este aspecto acabou sendo o motor que desencadeou o surgimento de inúmeras descobertas científicas e inovações tecnológicas por parte da Grã-Bretanha e que resultou no domínio britânico sobre a economia mundial no final do século XIX.

Ao longo do século $X X$, vários economistas tem se dedicado a explicar o crescimento econômico como algo muito ligado à localização das cidades e países, destacandose Marshall (1920) como um dos pioneiros neste tema, foi somente nos últimos quinze anos que cresceu a consciência por parte de alguns autores eminentes como Paul Krugman (1995), Peter Dicken (1998) ou Michael Porter (1993) a respeito da importância das condições geográficas para o desenvolvimento econômico. A razão para esta conscientização tem várias explicações, mas uma delas refere-se ao fato de que o progresso e as melhorias das condições de vida têm se concentrado de forma acentuada em algumas regiões do globo, por sinal, a grande maioria situada no hemisfério norte.

A análise da relação entre a mudança tecnológica e o desenvolvimento econômico também não é um assunto novo, tendo sido um dos temas principais de J. Schumpeter, um dos maiores economistas do início do século $X X$. Para Schumpeter (1943), a economia está normalmente em estado de equilíbrio em seus fluxos de capital, mas a atividade empreendedora e a inovação alteram esta tendência criando monopólios temporários e gerando riquezas. Após algum tempo, como decorrência da inovação ter se tornado madura e de outros competidores adentrarem o mercado, o equilíbrio torna a voltar, para, então, consequentemente, surgir outra inovação acompanhada de um empreendedor, a qual 
causará uma destruição criativa, mudando novamente a ordem econômica vigente. Ou seja, segundo Schumpeter, as inovações têm o poder de alterar equilíbrios existentes em setores e até de destruí-los totalmente para colocar algo novo em seu lugar. Não resta dúvida que Schumpeter está bastante atual.

Também datam do início do século $X X$ as análises do economista russo Kondratiev. De acordo com Kondratiev (1925), o crescimento econômico ocorre em ondas, onde cada uma delas tem uma duração aproximada entre 50 e 60 anos. Cada uma destas ondas está associada a alguma importante mudança tecnológica. Já aconteceram quatro ondas e estamos agora na metade da quinta, conforme mostrado no quadro 1 . Kondratiev dizia que a mudança tecnológica que caracteriza cada onda tem um impacto enorme sobre toda a economia e a sociedade no período da sua vigência. Cada onda, segundo ele, teria 4 subfases: 1. prosperidade com crescimento; 2 . recessão; 3. depressão e 4. decadência com substituição por uma nova onda. Assim sendo, inicialmente a nova onda provoca um grande crescimento econômico e enormes mudanças na sociedade, incluindo quebra de paradigmas e mudanças culturais. No entanto, ao final do período a demanda começa cair, além de haver uma saturação devido ao grande número de empresas competindo entre si. Nesse momento os investimentos também diminuem, as empresas se concentram em racionalização e o desemprego aumenta. É quando começa a surgir a próxima onda com base no aparecimento de alguma nova tecnologia revolucionária. O Quadro 1 - "As 5 ondas de Kondratiev" mostra as características principais das 4 ondas anteriores e a que estamos vivenciando agora, a quinta, que é a onda da Tecnologia da Informação.

A última linha do Quadro 1, mostra justamente quais os países que se saíram melhor em cada uma das 5 ondas. Dicken (1998), ao analisar os ciclos de Kondratiev, ressalta que em cada uma das fases, uma dada mudança tecnológica predominou e permitiu que algumas nações crescessem bem mais que outras, concluindo assim que só este fator já seria suficiente para que a questão geográfica fosse melhor compreendida no sentido de se tentar entender como surgem as inovações tecnológicas. Ou seja, a questão crucial é por que as inovações tecnológicas são muito freqüentes em algumas regiões e escasseiam ou não existem em outros espaços geográficos.

Michael Porter (1993), no final dos anos 80, passou a pesquisar o que havia de especial no ambiente de negócios de algumas nações que as tornava mais desenvolvidas e avançadas do que outras; assim como, por que em outros casos, nações não conseguiam avançar ou melhorar as condições de vida de suas populações. Desta forma no início dos anos 90, divulgou o resultado de uma pesquisa que abrangeu 10 países, infelizmente nenhum deles na América Latina, e a partir da mesma criou um modelo para análise de situações que ele mesmo denominou de "modelo do diamante". Uma das constatações iniciais de sua pesquisa é a de que não são as nações que são desenvolvidas ou poderosas economicamente, mas sim as empresas que têm sede nesses países. Ou seja, os Estados Unidos, por exemplo, têm uma importância enorme na economia mundial, mas esse mérito se deve ao grande numero de empresas com sede neste país que ocupam posições de destaque no cenário global.

Porter (1993) enfatiza que a prosperidade das Nações depende da melhoria dos fundamentos microeconômicos da competição. Isso está intimamente relacionado com fatores estritamente locais tais como a existência de clusters, o tipo de demanda criada por parte dos consumidores, o grau da rivalidade entre as empresas, as estratégias adotadas pelas mesmas, além de aspectos bem regionais, como recursos naturais, competências especificas e qualificações em recursos humanos.

Michael Porter possui um artigo clássico por ele juntamente com Scott Stern em 2002 
Quadro 1: "As 5 ondas de Kondratiev", extraído de Dicken, P.( 1998)

\begin{tabular}{|c|c|c|c|c|c|}
\hline ONDA: & Primeira & Segunda & Terça & Quarta & Quinta \\
\hline $\begin{array}{l}\text { Início e } \\
\text { Término }\end{array}$ & $\begin{array}{l}1770 / 80 a \\
1830 / 40\end{array}$ & $\begin{array}{l}1830 / 40 a \\
1880 / 90\end{array}$ & $\begin{array}{l}1880 / 90 a \\
1920 / 30\end{array}$ & $\begin{array}{l}1920 / 30 \mathrm{a} \\
1970 / 80\end{array}$ & $\begin{array}{l}1970 / 80 \\
a ?\end{array}$ \\
\hline Descrição & mecanização & $\begin{array}{l}\text { força a vapor e } \\
\text { ferrovia }\end{array}$ & $\begin{array}{l}\text { energia elétrica, } \\
\text { engenharia pesada }\end{array}$ & $\begin{array}{l}\text { produção em massa, } \\
\text { "fordismo" }\end{array}$ & $\begin{array}{l}\text { Tecnologias da } \\
\text { informação }\end{array}$ \\
\hline Fator-chave & $\begin{array}{l}\text { algodão e } \\
\text { ferro fundido }\end{array}$ & $\begin{array}{l}\text { carvão e } \\
\text { transporte }\end{array}$ & aço & petróleo e derivados & $\begin{array}{l}\text { microeletrônica, } \\
\text { tecnologia digital }\end{array}$ \\
\hline $\begin{array}{l}\text { Setores } \\
\text { alavancadores } \\
\text { de crescimento }\end{array}$ & $\begin{array}{l}\text { têxteis e seus } \\
\text { equipamentos, } \\
\text { fundição e } \\
\text { moldagem de ferro, } \\
\text { energia hidráulica }\end{array}$ & $\begin{array}{l}\text { máquinas e } \\
\text { navios a vapor, } \\
\text { máquinas ferramentas, } \\
\text { equipamentos } \\
\text { ferroviários }\end{array}$ & $\begin{array}{l}\text { engenharia e } \\
\text { equipamentos } \\
\text { elétricos, } \\
\text { engenharia e } \\
\text { equipamentos } \\
\text { pesados }\end{array}$ & $\begin{array}{l}\text { automóveis e } \\
\text { caminhões, } \\
\text { tratores e tanques, } \\
\text { indústria aeroespacial, } \\
\text { bens duráveis, } \\
\text { petroquímicos }\end{array}$ & $\begin{array}{l}\text { equipamentos de } \\
\text { informática e } \\
\text { telecomunicações, } \\
\text { robótica, } \\
\text { serviços info intensivos, } \\
\text { softwares }\end{array}$ \\
\hline Infra-estrutura & $\begin{array}{l}\text { canais, } \\
\text { estradas }\end{array}$ & $\begin{array}{l}\text { ferrovias, } \\
\text { navegação mundial }\end{array}$ & energia elétrica & $\begin{array}{l}\text { auto-estradas, } \\
\text { aeroportos, } \\
\text { caminhos aéreos }\end{array}$ & $\begin{array}{l}\text { redes e sistemas } \\
\text { "information highways" }\end{array}$ \\
\hline $\begin{array}{l}\text { Outros serviços } \\
\text { crescendo } \\
\text { rapidamente }\end{array}$ & $\begin{array}{l}\text { máquinas a vapor, } \\
\text { maquinaria }\end{array}$ & $\begin{array}{l}\text { aço, } \\
\text { eletricidade, } \\
\text { gás, } \\
\text { corantes sintéticos, } \\
\text { engenharia pesada }\end{array}$ & $\begin{array}{l}\text { indústria automobilística e } \\
\text { aeroespacial, } \\
\text { rádio e telecomunicações, } \\
\text { metais e ligas leves, } \\
\text { bens duráveis, } \\
\text { petróleo e plásticos }\end{array}$ & $\begin{array}{l}\text { fármacos, } \\
\text { energia nuclear, } \\
\text { microeletrônica, } \\
\text { telecomunicações }\end{array}$ & $\begin{array}{l}\text { biotecnologia, } \\
\text { nanotecnologia, } \\
\text { atividades espaciais }\end{array}$ \\
\hline $\begin{array}{l}\text { Países } \\
\text { líderes }\end{array}$ & \begin{tabular}{|l} 
Grã-Bretanha, \\
França e Bélgica
\end{tabular} & $\begin{array}{l}\text { Grã-Bretanha, } \\
\text { França, Bélgica, } \\
\text { Alemanha e EUA }\end{array}$ & $\begin{array}{l}\text { Alemanha, EUA, } \\
\text { Grã-Bretanha, } \\
\text { França, Bélgica, } \\
\text { Suíça e Holanda }\end{array}$ & $\begin{array}{l}\text { EUA, Alemanha, } \\
\text { outros países da CEE, Japão } \\
\text { Rússia, Suécia, Suiça }\end{array}$ & $\begin{array}{l}\text { Japão, EUA, Alemanha, } \\
\text { Suécia, outros países da } \\
\text { CEE, Taiwan e Coréia }\end{array}$ \\
\hline
\end{tabular}

publicado na Sloan Management Review, denominado "Innovation: location matters". Neste artigo, Porter e Stern criticam a ênfase que normalmente tem sido dada à discussão a respeito do ambiente interno das empresas como um fator preponderante para o surgimento de inovações tecnológicas. Segundo os autores "... o ambiente externo é, no mínimo, tão importante quanto o interno para a inovação..." e prosseguem dizendo que a localização geográfica é crucial para a inovação e que a gestão das inovações pelas empresas, deve ser feita de acordo com a região onde a empresa está instalada. Segundo Stern e Porter, a fertilidade da localização geográfica no tocante à inovação também varia significativamente conforme o setor de atividade, e exemplificam: Os Estados Unidos ofereceram um ambiente particularmente atraente para inovação em produtos farmacêuticos nos anos 90, ao mesmo tempo em que a Suécia e a Finlândia atingiram extraordinários índices de inovação na área de comunicação sem fio.

Ao chamar a atenção para a importância da geografia e do espaço no surgimento de inovações tecnológicas, Peter Dicken (1998) destaca quais são estes aspectos locais que devem ser levados em consideração: "....... a geografia desempenha um papel fundamental no processo de inovação e aprendizagem, na medida em que as inovações na maioria das vezes são menos o resultado de empresas individuais $e$ sim as de um conjunto de recursos, conhecimentos e outros inputs e capacidades que estão localizados em lugares específicos. A reunião destes inputs como pesquisa \& desenvolvimento das universidades e das empresas, aglomeração de empresas manufatureiras em setores afins, e network de provedores de serviços acaba por criar economias de escala, facilidades no compartilhamento de conhecimento, e fertilização cruzada de idéias promovendo interações cara a cara que acabam por permitir a verdadeira 
transferência de tecnologia......".

Mas e a América Latina? Um dos objetivos do presente artigo é justamente tentar estabelecer as relações entre as condições geográficas da América Latina e o surgimento de inovações tecnológicas no interior das grandes empresas locais. Além de procurar mostrar em quais setores da economia local estariam as melhores condições para tal desenvolvimento.

\section{América Latina}

\section{II- O panorama tecnológico da}

Até o início do século XVI alguns dos povos que habitavam a América Latina, principalmente astecas, maias e incas, detinham conhecimentos científicos e tecnológicos muitas vezes superiores aos que, à mesma época, existiam na Europa ou na China. Em algumas áreas como astronomia, botânica, farmacologia e metalurgia, os espanhóis assimilaram os conhecimentos adquiridos na região e os disseminaram pela Europa.

Hoje, no entanto, a América Latina deixou de ser um importante provedor de conhecimentos científicos e tecnológicos, pois apesar de representar cerca de $9 \%$ da população mundial, a região como um todo, corresponde a apenas $1,6 \%$ do total investido globalmente em Ciência \& Tecnologia. Segundo a OCDE - Organização para a Cooperação Econômica e o Desenvolvimento, no ano 2001, o mundo investiu cerca de 587 bilhões de dólares nesta área. Do total deste investimento apenas 9,4 bilhões foram gastos pelos países latino americanos. Isto representou cerca de 0,7 $\%$ do PIB somado dos países da região, o que não deixa de representar um avanço em relação aos anos 80. Naquele período, a média de gastos dos países da região com pesquisa e desenvolvimento em relação ao PIB foi de

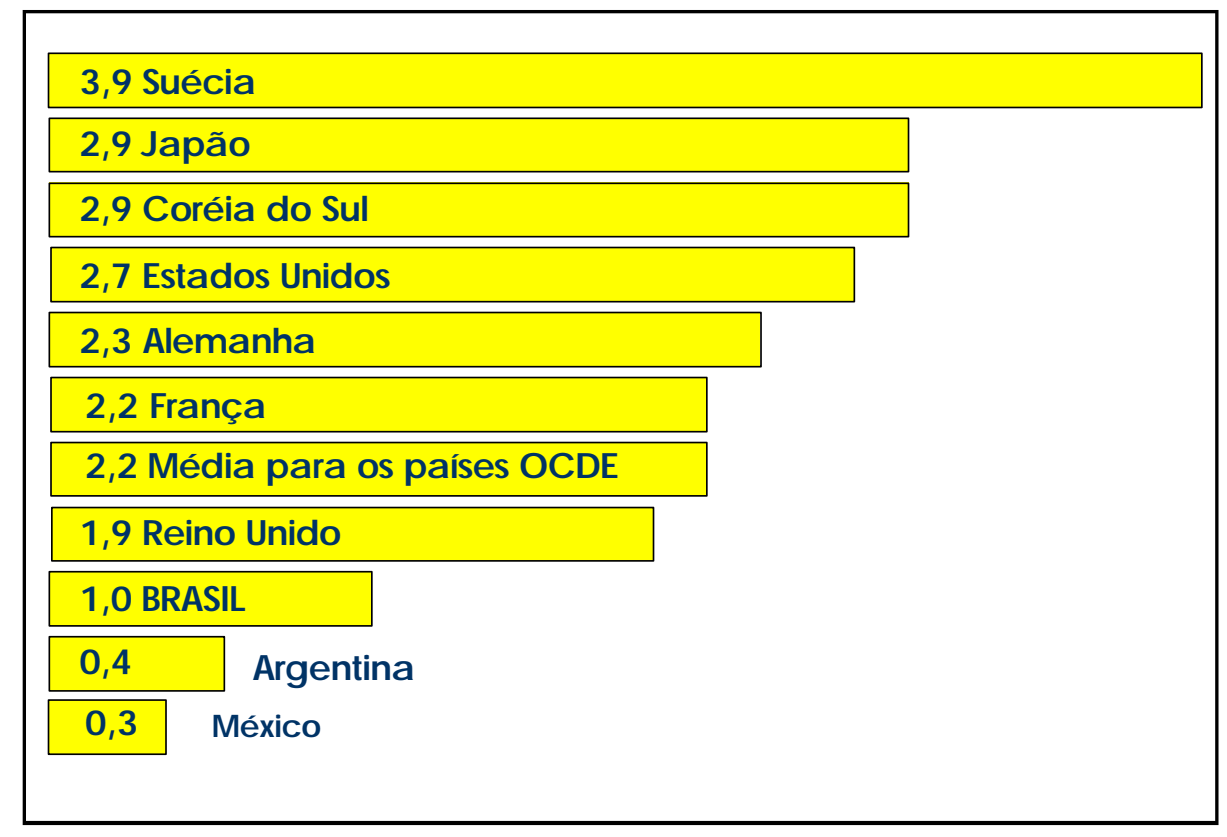

Quadro 2- Gastos de alguns países em Ciencia \&Tecnologia em relação aos PIBs em 2003. Conforme site da OCDE - www.oecd.org 
apenas $0.45 \%$ (Malecki 1997), contra 2,0 \% na média européia e 2,9 \% nos Estados Unidos.

o quadro 2 -Investimentos de alguns países em Ciencia\&Tecnologia em relação aos PIBS naquele ano, mostra quanto alguns países investiram em P\&D em 2003 segundo a OCDE. Por ele se percebe que mesmo o país latino americano que mais gasta com $P \& D$, que é o Brasil, está muito abaixo do que gastam os países desenvolvidos. Este é um problema crônico da região que só tem se acentuado com o tempo. O papel da América Latina na área de Ciência \& Tecnologia mundial é cada vez menor. Este fato é confirmado sempre que alguma análise global acerca dos paises mais fortes é feita nessa área.

Erber (2000) aponta três razões estruturais para comprovar a dificuldade e a pouca atenção com a questão tecnológica no continente latino-americano:

1. A desproporção entre o peso econômico da região e os esforços feitos em $C \& T$, sejam eles expressos pelos gastos com pesquisa e desenvolvimento ou pelo número de publicações cientificas e patentes depositadas nos EUA.

2. O claro desempenho melhor em atividades científicas do que em atividades tecnológicas

3. O predomínio de tecnologias importadas, provocando uma limitada articulação entre atividades científicas e tecnológicas na região.

Freeman \& Soete (1997) fazem uma retrospectiva histórica do que aconteceu na região, destacando que até o início dos anos 50 , o desenvolvimento industrial em toda América Latina caracterizou-se pelo reduzido grau de sofisticação tecnológica e pela simples importação de tecnologia, principalmente dos Estados Unidos e Alemanha, que vinha incorporada aos bens de capital. A partir da segunda metade dos anos 50, vários países introduziram medidas de proteção aos seus respectivos mercados nacionais tentando eliminar ou substituir as importações.
Foi nesta época que países da região começaram a produzir bens de consumo durável e bens intermediários com maior complexidade tecnológica. A estratégia seguida basicamente por Brasil, Argentina e México foi a de buscar investimento por parte de empresas estrangeiras, principalmente no segmento das montadoras de automóveis. Os respectivos governos também investiram, mas nos segmentos de maior prazo de maturação, como os de matérias primas e de infra-estrutura, mas não em setores de média ou alta densidade tecnológica. O que ocorreu é que se avolumou muito a importação explicita de tecnologia e de serviços tecnológicos sem que houvessem esforços internos aos países para absorver essas tecnologias.

Desde meados dos anos 60, em todos estes países, assiste-se à criação de vários institutos e centros de Pesquisa \& Desenvolvimento de caráter público. No entanto, poucos foram aqueles que mereceram verbas e atenções especiais dos respectivos governos. Apesar disso, alguns deles foram decisivos para a criação de pesquisa de qualidade nos setores econômicos em que atuam ou atuaram e hoje desempenham um papel fundamental. Apenas para ficar em dois exemplos brasileiros, destacase o CTA - Centro Tecnológico da Aeronáutica que é considerado o principal responsável pelo sucesso da Embraer e a EMBRAPA - Empresa Brasileira de Agropecuária considerada responsável pela maior parte das pesquisas que resultaram no enorme aumento da produtividade da agricultura brasileira nos últimos anos. Malecki (1997) considera que o que aconteceu no Brasil nestas duas áreas deveria ser um modelo do que deve ser seguido por outros países latino americanos.

Ainda segundo Malecki, o panorama geral da tecnologia na América Latina mostra que as instituições são fracas e as interferências ou atuações políticas predominam, o que acaba acarretando na falta de estratégias de longo prazo para ciência \& tecnologia e no pouco envolvimento do setor privado, como iremos discutir posteriormente na seção 4 do presente artigo. 
III- Enquadramento das grandes empresas latino americanas de acordo com a densidade tecnológica dos setores em que atuam.

O objetivo desta seção é demonstrar que nem mesmo as maiores empresas latino americanas podem ser consideradas como expressivas e atuantes nas áreas em que ocorrem os mais importantes desenvolvimentos tecnológicos. Malecki (1997) menciona que os dois indicadores mais utilizados para definir o que são setores de alta tecnologia são: 1. intensidade dos esforços em pesquisa e desenvolvimento em cada setor, medida pela percentagem das vendas que é gasta com $P \& D$ e 2. pela percentagem de trabalhadores de formação técnica, como engenheiros, cientistas e tecnólogos em relação ao total de trabalhadores do setor. Com base nestes critérios, Malecki apresenta uma tabela elaborada pela OECD em 1995 classificando 23 setores econômicos industriais em 3 categorias - Alta, Média e Baixa Densidade Tecnológica, sendo que as proporções dos gastos em $P \& D$ sobre o total das vendas eram, em média, em cada categoria de $8,1,2,5$ e 0,5 , respectivamente. $\mathrm{O}$ quadro 3 lista estes setores, conforme classificados pela OECD, em cada uma das 3 categorias acima citadas. Conhecendo

Quadro 3 - Classificaçẫo dos setores eoonômicos conforme a densidade tecnológica

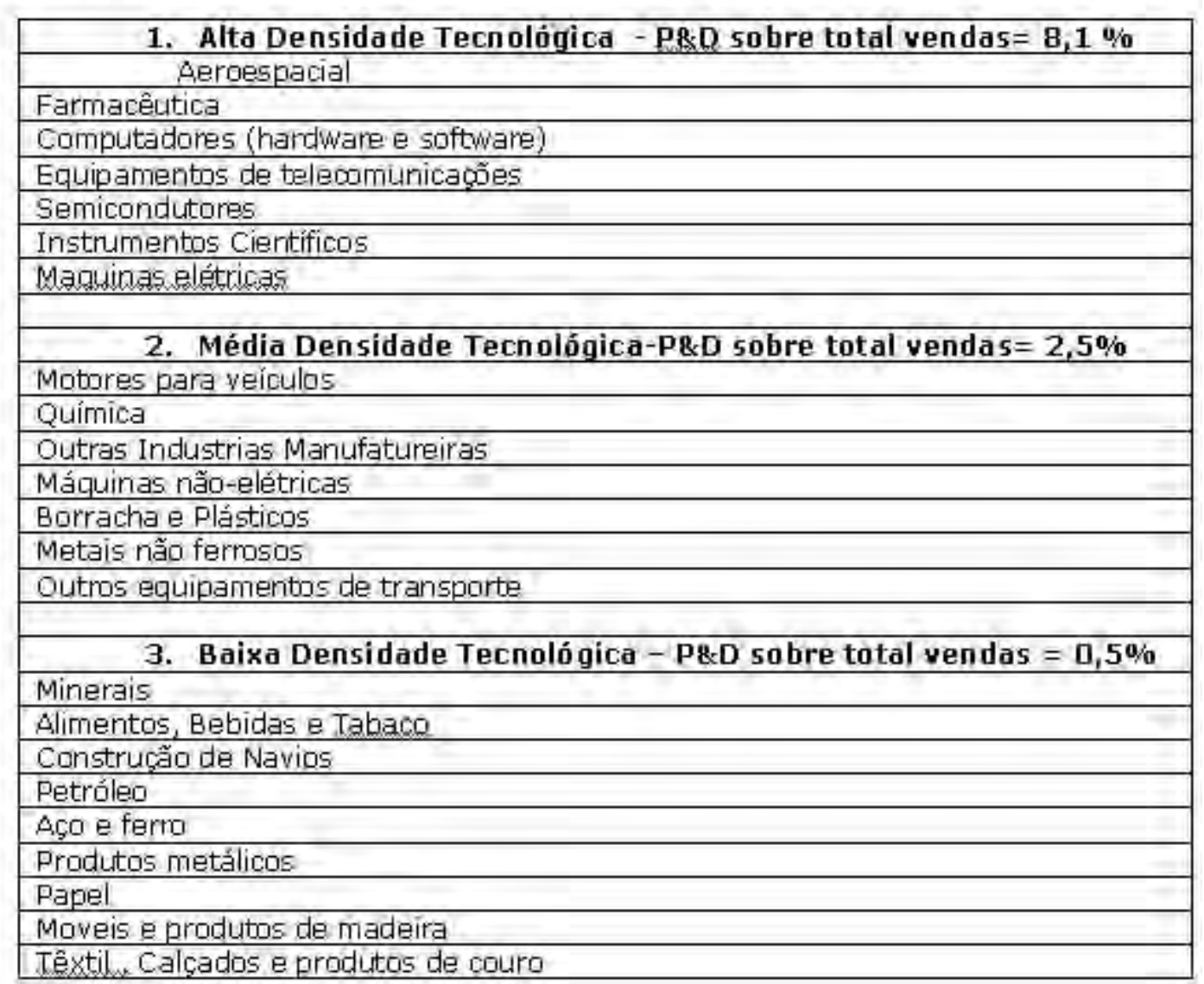


quais são os setores industriais de alta, média e baixa intensidade tecnológica vamos agora pesquisar em quais deles podemos aglutinar as grandes empresas da América Latina. Para isso precisamos, antes de mais nada, obter a relação das mesmas, o que poderia ser feito de diversas formas, no entanto optamos por recorrer às revistas especializadas na elaboração de rankings de maiores empresas. Julgamos válido consultar 4 publicações: AmericaEconomia,
Business Week, Forbes e Latin Trade.

A revista Business Week publica anualmente a relação das 1200 maiores empresas por valor de mercado. Em sua última edição constavam 35 empresas latinoamericanas das quais 20 fazem parte de setores ligados a serviços como bancos e varejo, restando, portanto, apenas 15 empresas ligadas às atividades industriais. Estas 15

Quadro 4- As maiores empresas industriais da América Latina por país e por setor da economia

\begin{tabular}{|c|c|c|c|c|c|}
\hline & ARGENT. & BRASIL & CHILE & MÉXICO & OUTROS \\
\hline AEROSPACIAL & & Embraer & & & \\
\hline $\begin{array}{l}\text { ALIMENTOS/BEBIOAS } e \\
\text { TABACO }\end{array}$ & Arcor & $\begin{array}{l}\text { Sadia, Ambev, } \\
\text { Perdigà }\end{array}$ & & $\begin{array}{l}\text { Modelo, Lala } \\
\text { Bimbo,Femsa } \\
\text { Gruma Cigatam }\end{array}$ & $\begin{array}{l}\text { Bavaria } \\
\text { (CoL) e } \\
\text { Polar (VEN) }\end{array}$ \\
\hline MAKUFATURA.(auto-peças) & 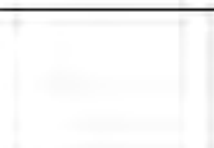 & & & $\begin{array}{l}\text { Desc } \\
\text { Carso, Xignux, } \\
\text { Nemak,Saltillo, } \\
\text { e Santuiz }\end{array}$ & \\
\hline EXTRACAOO & & Vale, MBR & $\begin{array}{l}\text { Antofagast } \\
\text { a, SQM. }\end{array}$ & BAL e México & $\begin{array}{l}\text { Southern } \\
\text { Peru (Peru) }\end{array}$ \\
\hline ELETROELETRONI. & & & & Mabe & \\
\hline$A C O$ & $\begin{array}{l}\text { Tenaris/Techi } \\
\text { nt e Siderar }\end{array}$ & $\begin{array}{l}\text { Gerdau, Usiminas, } \\
\text { CSN, Tubarăo }\end{array}$ & Molymet & $\begin{array}{l}\text { IMSA, Villacero, } \\
\text { Hylsamex, Alfa e } \\
\text { Altos Hornos }\end{array}$ & Sidor (ven $k$ \\
\hline PAPEL/ CELULOSE & & $\begin{array}{l}\text { Aracuiz, Suzano, } \\
\text { Klabin, Cenibra }\end{array}$ & $\begin{array}{l}\text { Celco, } \\
\text { CMPC, } \\
\text { Arauoo }\end{array}$ & Durango & \\
\hline MATERIAIS não FERRQSOS & Aluân & $\begin{array}{l}\text { Votorantim, Albras, } \\
\text { CBA }\end{array}$ & & Cemex, Vitro & \\
\hline PETROLEO & & Ipiranga, Petrobras & & Pemex & $\begin{array}{l}\text { PDVSA } \\
\text { Pien }\end{array}$ \\
\hline QUIMICA E PETROQUIMICA & & $\begin{array}{l}\text { Ultra } \\
\text { Braskem,Copesul, }\end{array}$ & Copec & 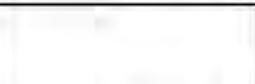 & $\begin{array}{l}\text { La Pampilla } \\
\text { (Peru) }\end{array}$ \\
\hline TOTAL & 4 & 22 & 7 & 24 & 6 \\
\hline
\end{tabular}

Obs; Este quadro foi elaborado pelo autor pesquisando as revistas AmericaEconomia, LatinTrade, Forbes e Business Week. 
empresas estão incluídas juntamente com as demais empresas que compõe o Quadro 4 mostrado na página 33. Já a revista Forbes, apresenta anualmente a relação das 2000 maiores empresas do mundo, por meio de um critério misto que considera para cada empresa, o seu valor de mercado, ativos, faturamento e lucros. Dessas organizações listadas, apenas 46 são latino-americanas das quais 21 atuam em setores industriais: todas também se encontram na lista mostrada no Quadro 4 - As maiores empresas industriais da América Latina por país e por setor da economia. (V.pagina 16). O quadro 4 lista as principais empresas industriais da América Latina por país de origem e por setor industrial, e foi elaborado com base nas listas das duas revistas acima mencionadas e mais as listas das revistas AmericaEconomia e LatinTrade. Usamos um critério misto que ponderou igualmente faturamento e valor de mercado das empresas para escolher as 63 maiores.

Quadro 5 - As maiores empresas do mundo em investimento de $P \& D$ em bilhões de dolares no ano 2004

\begin{tabular}{|lc|}
\hline & 7,78 \\
1. Microsoft & 7,68 \\
2. Pfizer & 7,40 \\
3. Ford & 7,03 \\
4. Daimler- Chrysler & 7,02 \\
5. Toyota & 6,50 \\
6. General Motors & 6,16 \\
7. Siemens & 5,73 \\
8. Matsushita Electric & 5,67 \\
9. IBM & 5,20 \\
10. Johnson \& Johnson & 5,20 \\
11. GlaxoSmithKline & 4,78 \\
12. Intel & 4,72 \\
13. Volkswagen & 4,67 \\
14. Sony & 4,64 \\
15. Nokia & 4,35 \\
16. Honda & 4,32 \\
17. Samsung Electronics & 4,20 \\
18. Novartis & 4,07 \\
19. Roche & 4,01 \\
20. Merck & \multicolumn{2}{|c|}{ Fonte : Booz Allen - $\mathbf{w w w . b a h . c o m ~}$} \\
\hline
\end{tabular}

O que se vê, pelo quadro 4 , é que das 63 maiores empresas latino-americanas, 46 empresas tem sua sede ou no México ou no Brasil. Interessante agora, enquadrarmos estas organizações nos setores mencionados das 3 categorias de Malecki: Alta, Média e Baixa densidade tecnológica. Assim percebemos que aparecem apenas dois setores de alta tecnologia, que são o setor aeroespacial e o eletroeletrônico. Há três setores considerados de media densidade tecnológica, que são o químico, o de manufaturas e o de não ferrosos. E finalmente há cinco setores de baixa densidade tecnológica que são os restantes: Alimentos e Bebidas, Extração, Aço, Papel e Celulose e Petróleo. Dessa forma verificamos que das 63 maiores empresas latino americanas apenas duas, Embraer e Mabe, podem ser consideradas como de alta tecnologia. Há 17 empresas que se enquadram entre os setores de média intensidade tecnológica e a grande maioria das 63 empresas, ou seja, 44 (70\%) organizações referem-se a setores de baixa intensidade tecnológica.

Esses dados e um outro importante estudo recente, feito pela Booz Allen acerca das 1000 maiores empresas do mundo por gastos na busca de inovações tecnológicas, indicam que a situação das empresas latino-americanas é realmente ruim. Nesta pesquisa, denominada "Money isn't everything - Booz Allen Hamilton Global Innovation 1000", realizada e divulgada em 2005, a Booz Allen fez um extensivo levantamento junto às maiores empresas do mundo para verificar quanto cada uma investia com pesquisa \& desenvolvimento e desta forma estabeleceu um ranking dos gastos por empresas. As vinte primeiras com os respectivos gastos em $P \& D$ em bilhões de dólares no ano 2004 estão mostradas no quadro 5.

Nesta relação das 1000 empresas aparece uma única da América Latina que é a brasileira Petrobras, que está na posição 277, com um gasto em $P \& D$ de 238 milhões de dólares em 2004, o qual representou apenas $0,6 \%$ do seu faturamento de 37 bilhões de dólares. Sem dúvida este é um dos dados mais preocupantes do estudo da Booz Allen, ou seja, a quase total 
ausência de empresas latino americanas nesta relação. Mas há outras importantes informações neste estudo que também não são animadoras, como por exemplo, o fato de que em 2004 estas 1000 empresas investiram 384 bilhões de dólares em P\&D dos quais 96,8 $\%$ foi investido por empresas com sede no primeiro mundo. Ou seja, apenas 3,3\% do total foi gasto por empresas com sede na China, Índia, América Latina e outras regiões de países emergentes. Outro dado interessante é a origem por setores da economia das 1000 empresas e, consequentemente, em quais setores o gasto com $P \& D$ é maior. Para essa análise 0 estudo classificou as 1000 empresas em 11 categorias de setores, mostrados no quadro 6, acompanhados da informação de quanto do total de 384 bilhões de dólares foi gasto em cada setor em P\&D em 2004. Se voltarmos para o quadro 4, onde estão apontadas as 63 maiores empresas latino americanas, veremos que nenhuma delas faz parte dos dois setores mais importantes do ponto de vista de gastos em tecnologia, segundo este estudo da BozzAllen e que são os setores de Saúde (aí incluída a indústria farmacêutica) ou o de Software. Na próxima seção analisamos este aspecto.

\section{IV- $O$ porquê do pequeno envolvimento das empresas e das nações latino-americanas com as tecnologias.}

A abundância de recursos naturais na América Latina, tem sido apontada como uma explicação importante para a baixa preocupação com a inovação que predomina na região. Lindsay \& Fairbanks (2000) afirmam que os empresários locais tendem a pressupor que as vantagens em recursos naturais, matérias primas abundantes e mão de obra barata, vão Ihes proporcionar posições de liderança nos mercados exportadores e, assim, deixam de criar condições para a inovação. Adotando essa filosofia, são constantemente ultrapassados por países da Ásia ou da África, que conseguem ou baratear ainda mais o custo de sua mão de obra, ou entram no mercado internacional vendendo um recurso natural a um preço ainda mais baixo do que vinha sendo praticado por eles. Além disso, Lindsay \& Fairbanks (2000) apontam outra razão importante para a inexistência de inovações: trata-se da cooperação deficiente entre as empresas. Segundo eles não existe a cultura da cooperação entre as empresas da região, ao contrario de países como a Itália, onde a existência dos "clusters", também chamados de agrupamentos industriais, promovem a cooperação e incentivam com que as empresas se unam para, por exemplo, buscar

Quadro 6 - Gastos em PQD em cada setor da economia em bilhões de dólares em 2004

\begin{tabular}{|lcc|}
\hline 1. Tecrologia da Informação e Eletrônica & $\$ 96,2$ & $25 \%$ \\
2. Saúde (Farmacêutica) & $\$ 79,2$ & $21 \%$ \\
3. Automobilística & $\$ 69,4$ & $18 \%$ \\
4. Tecnologia (inclui maquináno pesado) & $\$ 29,8$ & $8 \%$ \\
5. Energia e Química (inclui petróleo) & $\$ 25,5$ & $7 \%$ \\
6. Software e Internet & $\$ 20,5$ & $5 \%$ \\
7. Industrias manufatureiras em geral & $\$ 18,2$ & $5 \%$ \\
8. Consurno & $\$ 14,3$ & $4 \%$ \\
9. Aeroespacial e Defesa & $\$ 12,2$ & $3 \%$ \\
10. Telecom & $\$ 8,8$ & $2 \%$ \\
11. Outros & $\$ 9,8$ & $2 \%$ \\
TOTAL & $\$ 384$ & $100 \%$ \\
\hline
\end{tabular}

Fonte: Booz Allen - www,bah,com 
conjuntamente mercados externos, lançar uma nova marca, ou então investir conjuntamente em $P \& D$ - Pesquisa \& Desenvolvimento, na América Latina quase que invariavelmente os empresários só enxergam nos concorrentes um inimigo que deve ser abatido.

Isso contribui para criar um clima de desconfiança dentro de cada setor que sempre aniquilou qualquer possibilidade de cooperação. Honrosas exceções constituem-se as montadoras automobilísticas e suas relações com as fornecedoras de autopeças tanto na Argentina, como no Brasil ou no México. Mas este desvio da regra, provavelmente, deva-se ao fato destes serem setores onde ocorre a predominância do capital estrangeiro.

Essa ausência de cooperação empresarial também explica o pequeno numero de clusters na região e como reafirmam Lindsay e Fairbanks (2000) : " ...notamos uma profunda ausência de clusters de setores correlatos ou de apoio, e uma correspondente falta de inovação: empresas que não cooperam entre si não são capazes de aprender umas com as outras. "

Peter Dicken (1998) enfatiza que uma característica importante no desenvolvimento de países do terceiro mundo sejam eles asiático ou latino americanos é a forte presença do Estado. No entanto, este autor assinala o fato de que na América Latina os governos não foram tão bem sucedidos como na Ásia. Segundo ele, a razão principal para este insucesso dos vários governos desses países, foi a falta de preocupação com o aumento da capacitação interna com vistas à aumentos de exportações. Enquanto na Ásia, a preocupação maior era o crescimento das exportações de produtos industrializados, na América Latina a ênfase era na substituição de importações.

Dicken chama a atenção para o fato de que a antiga divisão de trabalho, quando as nações desenvolvidas produziam bens manufaturados e as nações em desenvolvimento vendiam suas commodities, sejam estas minerais ou produtos agrícolas, não é mais válida. Hoje o fluxo de mercadorias pelo mundo é extremamente complexo e se tornou possível graças à fragmentação das cadeias produtivas. No entanto, o que vemos na prática é a existência de algumas cadeias produtivas que se estendem por vários países da América Latina, mas que são quase que totalmente comandadas por empresas com sede em países do primeiro mundo. Como exemplos dessas cadeias podemos citar os setores automobilísticos, farmacêutico, equipamentos de informática e de telecomunicações, o setor de bens eletrônicos de consumo, e o setor químico.

De uma forma geral, as empresas destes setores estão na América Latina em busca do rentável mercado, cujo tamanho não é pequeno, e também na intenção de obter mão de obra barata, para empregar em suas linhas de produção, o que na grande maioria dos casos se limita à montagem final de bens. Qualquer etapa do vasto processo das cadeias de valor das empresas globais deixará de ser realizado nas respectivas subsidiarias da América Latina, se nesta etapa houver necessidade de algum desenvolvimento tecnológico. Nesta hipótese, será realizada certamente na sede principal destas empresas que em geral está ou na América do Norte, ou na Europa ou no Japão.

Larrain (in Gwynne, 1999) ao explicar por que a América Latina não avançou tanto como a Ásia nos últimos 20 anos, atribui boa parte deste atraso ao fechamento de mercado e ao protecionismo que predominou em nossa região nos anos 70 e 80 ; isto por que esta suspensão não expôs as empresas da região à competição internacional, e também acabou adiando a construção da infra-estrutura para que os pesquisadores locais adquiríssem os meios necessários para desenvolver seus trabalhos.

Nessa mesma linha de pensamento, Chris Freeman e Luc Soete (1997) ao compararem o desenvolvimento econômico de algumas nações da Ásia, especialmente Coréia do Sul e Taiwan, com o progresso da América Latina na década nos 80 , chamam a atenção 
para a importância das diferenças que existem em alguns poucos aspectos abaixo enumerados. Estes aspectos, segundo os autores, que foram decisivos para explicar o enorme crescimento dos tigres asiáticos e a estagnação das nações latino americanas naquele período. Para eles, as cinco deficiências abaixo citadas estão entre os principais problemas do continente quando comparado com os tigres asiáticos.

1. Sistema Educacional deteriorado com baixa formação de engenheiros.

2. Muita transferência de tecnologia, especialmente dos Estados Unidos, mas baixa capacidade de absorção devido ao pequeno investimento das empresas locais em Pesquisa \& Desenvolvimento. Tecnologia.

3. Fraca infra-estrutura de Ciência \&

4. Atraso no desenvolvimento das telecomunicações

5. Nenhuma ênfase ao setor de produtos eletrônicos

Porém, existe algo que os governos possam fazer para tornar seus países mais férteis em inovações? Segundo Porter e Stern (2001), conforme mencionado no relatório já referido anteriormente a resposta é sim. Mas com ressalvas, pois os governos são apenas um dos componentes de um grande conjunto de fatores presentes no ambiente empresarial dos países que afeta a capacidade de inovação. $E$, seguramente, segundo eles, não é o fator mais importante.

Para que um dado setor econômico de um determinado país tenha propensão a inovar existem dez fatores cruciais. Estes pontos já haviam sido identificados por Porter em seu livro "A Vantagem Competitiva das Nações". No entanto, nesta ocasião sua preocupação era mostrar o que faz com que um setor econômico em um determinado país consiga ter projeção e sucesso mundial. Agora, com Stern, Porter arrola praticamente o mesmo conjunto de fatores, mas enfatizando que são eles que garantem o surgimento de inovações. Não se pode discordar de Porter de que se um dado setor econômico em um país é palco de inovações tecnológicas bem sucedidas, então há grandes chances de que este mesmo setor venha a ser considerado de excelência mundial. Os fatores considerados importantes por Porter e Stern são os seguintes:

1. Recursos Humanos de alta qualidade

2. Sólida Infra-estrutura de pesquisa em Universidades

3. Infra-estrutura de informação de alta qualidade

4. Ampla oferta de capital de risco

5. Presença de clusters em vez de empresas isoladas

6. Rede de fornecedores de alta competência/ excelência

7. Consumidores exigentes e demandantes de qualidade e sofisticação

8. Consumidores que criam a demanda de forma pioneira e inédita antes que outros consumidores em outros países o façam

9. Intensa rivalidade entre as empresas locais do setor em questão

10. Contexto local que encoraje o investimento em pesquisa

Ao percorrer este conjunto de 10 fatores, é fácil perceber que alguns deles realmente inexistem ou são muito fracos em toda a América Latina. Isso ocorre principalmente nosseguintes casos

2. Sólida infra-estrutura de pesquisa em Universidades

4. Ampla oferta de capital de risco

8. Consumidores que criam a demanda de forma pioneira e inédita antes que outros consumidores em outros países o façam

10.Contexto local que encoraje o investimento em pesquisa 
Um dos economistas contemporâneos mais respeitados e que mais tem estudado a relação entre desenvolvimento econômico e tecnologia é o premio Nobel de 2000, Joseph Stiglitz que escreveu juntamente com Carl Walsh um livro sobre Microeconomia em que destaca o papel da Tecnologia. Stiglitz \& Walsh (2003) mostram que as duas formas mais importantes e consensuais de que governos se devem utilizar para encorajar as atividades inovadoras são a proteção ao sistema de patentes e o apoio à pesquisa básica. Além disso, Stiglitz \& Walsh defendem que governos concedam subsídios para empresas desenvolverem novas tecnologias. Ao contrário de Porter e Stern (2001), eles são favoráveis a uma forte atuação governamental para favorecer o surgimento de inovações por parte das empresas. No entanto reconhecem que a atividade de pesquisa está cada vez menos ao alcance da pequena empresa por varias razões, mas principalmente pelo fato de bancos não concederem empréstimos para este tipo de atividade, fato que aumenta a importância dos subsídios, segundo Stiglitz \& Walsh.

No entanto, concessão de incentivos fiscais para projetos de pesquisa \& desenvolvimento é assunto pouco prioritário na agenda da grande maioria dos governos dos países latino-americanos. O país mais adiantado neste tema é o Brasil que apenas recentemente aprovou uma legislação de apoio à inovação, mas que apenas timidamente tateia a questão dos incentivos.

Cumpre destacar que Porter e Stern mencionam a América Latina e destacam como grandes vulnerabilidades da região no que diz respeito ao surgimento de inovações a pouca ligação entre as empresas e as universidades. Segundo eles "O sistema de ensino superior na América Latina tem pouca ligação com as empresas e muito pouco envolvimento com as políticas nacionais voltadas para ciência e tecnologia." Isto é confirmado por outros autores que se dedicaram a analisar a questão cientifica e tecnológica do continente. Sagasti (1981) aponta como um dos problemas crônicos da América Latina o enorme distanciamento entre a produção de ciência e a geração de tecnologia o que segundo ele é uma conseqüência da inexistência de relação entre a Universidade e a Empresa.

Esse mesmo aspecto é colocado por Millan B. \& Concheiro (2000) quando analisam as razões do atraso do México nas questões de Ciência \& Tecnologia. Estes vão além, mencionando que uma razão adicional para o atraso do país nesta questão, é a falta de uma política industrial que definisse as áreas prioritárias para investimentos, e deixam bem caracterizados que ao contrário dos países mais desenvolvidos onde quem mais investe em pesquisa \& desenvolvimento são as empresas, no caso do México esse gasto é em sua maior parte feito pelo governo. Assim enquanto no Japão, na Alemanha e Estados Unidos as empresas privadas são responsáveis respectivamente por $67,1 \%, 61,1 \%$ e $58,4 \%$ do total dos gastos com $P \& D$, no México esse valor é de apenas $17,6 \%$.

O mesmo ocorre com o Brasil, conforme mostrado no texto produzido pelo prof. Carlos Henrique Brito Cruz em 2002," A Universidade, a Empresa e a Pesquisa". Neste trabalho o Professor Cruz compara Brasil e Coréia em função do numero de engenheiros, cientistas e pesquisadores que trabalham ligados à pesquisa \& desenvolvimento. Apesar de o nosso país ter uma população quatro vezes superior a da Coréia, a quantidade de trabalhadores nessas funções é maior na Coréia chegando a 159773 pessoas, enquanto no Brasil totaliza 125645 pessoas, lembrando que, ambos os dados se referem a 2001. Mas no Brasil somente $23 \%$ destas pessoas estão em empresas privadas enquanto na Coréia esta porcentagem é de $59 \%$. Assim, a grande maioria dos brasileiros que trabalham em pesquisa, cerca de $77 \%$ do total dos pesquisadores, está ou na Universidade ou nos institutos mantidos pelo governo, enquanto na Coréia trabalham nestas instituições apenas $41 \%$ do total de pesquisadores.

Em 1999 a revista britânica Nature 
produziu uma edição especial chamada "Ciência na América Latina". No artigo dedicado ao México consta uma análise importante sobre um fato que ajuda a explicar os números acima e que se repete por todo o continente: - "Parte do problema é cultural. O México herdou a tradição européia do cientista como acadêmico e não o modelo norte-americano do cientista inventor e empresário. A ligação de um pesquisador universitário com a Indústria é considerado pelos colegas como uma forma de prostituição. Do lado da indústria, não há forte tradição de investimento em P\&D. Até o início dos anos 80, o México tinha uma política industrial de propriedade estatal e protecionismo que resultava em pouco incentivo ao investimento em inovação. Agora as empresas querem modernizar sua tecnologia, mas voltamse mais para as empresas estrangeiras atrás de ajuda, e não se mostram dispostas a esperar o tempo necessário para que a ciência e a tecnologia nacionais encontrem respostas para suas necessidades.".

Em suma, há várias razões para que o envolvimento das empresas e dos países da América Latina com desenvolvimento tecnológico seja pequeno. Mas para finalizar esta relação não se pode deixar de mencionar os aspectos culturais e a análise amarga de Montaner: " $A$ real tragédia da América Latina é que o capital é limitado e boa parte dele está em mãos de empresários não comprometidos com o risco ou com a inovação mas sim com a especulação.... Não são capitalistas modernos mas atuam como senhores da terra de tradição feudal."

\section{V- Considerações Finais}

A América Latina é muito rica em recursos naturais e de uma forma geral sua mão de obra é barata. Estes são os aspectos principais do seu espaço geografico que deram origem às grandes empresas originarias da região, com raríssimas exceções. Dessa forma, nosso continente ostenta algumas empresas poderosas, mas quase sempre atuantes em setores que foram importantes no século XIX, mas que deixaram de ser relevantes neste século $X X I$. Ter destque em setores como bebidas, cimento, mineração, agricultura, pesca ou aço não é de todo mau, mas não é suficiente. Como vimos, os países mais avançados contam com empresas nos setores que hoje dominam a economia mundial como telefonia, software, hardware, equipamentos médicos ou a indústria farmacêutica. Verificamos que mesmo as grandes empresas latino- americanas de uma forma geral estão fora dos setores de alta tecnologia, com raríssimas exceções como a brasileira Embraer ou a mexicana Mabe. Empresas do nosso continente quando conseguem porte e projeção para atuar no mercado mundial estão em setores de baixa tecnologia na maioria dos casos produzindo "commodities", Petrobras e Cemex são ótimos exemplos.

Nos países mais avançados quem mais gera inovações e tecnologia é a grande empresa, cabendo aos governos, o papel de criar as condições para que estas empresas possam florescer. Isto representa um problema para a América Latina, pois o número de grandes empresas é limitado quando comparado com o primeiro mundo. Entre as 2000 maiores empresas listadas na Business Week, aparecem apenas 46 empresas latino americanas e na relação das 500 maiores da Fortune apenas 7 são da nossa região.

Mesmo os grandes grupos empresariais latino americanos são pequenos (em termos de faturamento e patrimônio liquido) quando comparados aos grupos empresariais dos países desenvolvidos ou, até mesmo, de países como a Coréia e Taiwan. Como quase todos os setores industriais e de serviços estão se concentrando, tamanho passa a ser fundamental. A empresa que tem uma grande dimensão possui também capacidade administrativa, mercadológica e tecnológica por causa das economias de escala. Tanto a economia japonesa como a coreana cresceram baseadas num modelo de conglomerados composto por grandes empresas em torno dos quais giram outras empresas médias e pequenas. Estas grandes organizações foram muito competentes em difundir suas marcas pelo 
mundo o que foi feito com grande sucesso, bastando citar Sony, LG, Toyota ou Hiunday.

Os governos dos países mais avançados já perceberam, há tempos, que a competitividade das nações é resultado da competitividade de suas empresas e que, portanto, o que lhes compete é criar as condições para que suas empresas locais possam concorrer a nível internacional. Por isso, dão todo o suporte necessário ao desenvolum ento da ciência \& tecnologia, pois quem cria as novas tecnologias são as empresas, que como mostrou o estudo da Booz Allen, investem somas enormes em $P \& D$. Eles sabem, também, que nenhuma nação pode ser auto-suficiente em todas as tecnologias. Assim, por exemplo, os Estados Unidos se aperfeiçoaram e criam tecnologia em áreas como farmacêutica, informática e telecomunicações, a Alemanha em mecânica, o Japão em robótica, e a Inglaterra em biotecnologia e genética.

Apesar da importância das empresas na geração de tecnologia, como o presente artigo procurou deixar claro, é inegável que a solução dos problemas não cabe somente a elas: algumas medidas de apoio governamental se fazem necessárias, e a principal delas é a de estimular a formação de grandes conglomerados e a de apoiar a formação de clusters.

Mas é claro que o tratamento desta questão é extremamente difícil para os vários governos da região: sem grandes grupos, fortes e saudáveis, e com administração profissional não teremos como competir no difícil cenário da globalização. Também sem agrupamentos horizontais e verticais de empresas afins, ou seja, os "clusters", não alcançaremos nem economias de escala, nem desenvolvimento tecnológico.

Basear seu desenvolvimento em recursos naturais não é a única característica referente à geografia da região que afeta a existência ou não de inovações tecnológicas. O baixo investimento em educação, a pequena infra-estrutura destinada à pesquisa e mesmo a cultura conservadora e pouco arrojada de empresários que viveram muito tempo sem a necessidade de competir com produtos estrangeiros acabam por explicar a pequena presença da América Latina, no que há de relevante em Ciência \& Tecnologia no mundo de hoje.

\section{Bilbiografia}

BLACK , J.K. Latin America its problems and its promise. USA : Boulder, 1998

BLAKEMORE,H.,COLLIER,S. \& SKIDMORE, T. Latin America and the Caribbean. New York: Cambridge University Press, 1992.

BOOZALLEN - Money Isn't Everything- The Booz Allen Hamilton Global Innovation 1000. NewYork, 2005. Disponivel em http:// www.boozallen.com/publication/ strategy+business/Winter2005. Acesso em 31.8. 2006

BRAKMAN,S. ; GARRETSEN ,H.; VAN MARREWIJK ,C. An Introduction to geographical economics . Cambridge : University Press, 2005
BRITO CRUZ, C.H. A Universidade, a Empresa e a Pesquisa. Instituto de Física Gleb Wataghin, Universidade Estadual de Campinas. Disponível em http://www.ifi.unicamp.br/ brito/artigos/ univ-empr-pesq-rev102003b.pdf Acesso em 31.8.2006

DEL POZO, P. Aspectos Tecnologicos de la Modernization Industrial de Mexico. Mexico : Fondo de Cultura , 1995

DICKEN ,P. Global Shift . New York : The Guilford Press , 1998.

ERBER ,F. Perspectivas da América Latina em Ciencia \& Tecnologia . UFRJ, mimeo, 2002

FAIRBANKS,M. \& LINDSAY,S. Arando o Mar 
:Fortalecendo as fontes ocultas de crescimento em países em desenvolvimento. Rio de Janeiro : Qualitymark ,2000.

FREEMAN, C. \& SOETE, L. The economics of Industrial Innovation. Cambridge : MIT Press, 1997.

FORBES - The biggest companies in the world edição de 17 de abril de 2006

GALEANO,E. OpenVeins of Latin America: Five Centuries of the pillage of a continent. New York: Monthly Review Press, 1997

GWYNNE,R. \& KAY,C. Latin America transformed. London: Arnold, 1999.

KONDRATIEFF, N. The long wave in economic life. Review of Economic Statistics, vol 17 pp 105-15，1925

KRUGMAN, P. Development, Geography and Economic Theory . Cambridge : MIT Press, 1995

LANDES,D. Riqueza e a Pobreza das Nações : Por que algumas são tão ricas e outras são tão pobres. Rio de Janeiro: Campus , 1998.

MACILWAIN. C. As chances da América Latina. Nature . Número 398 . Abril 1999.

MALECKI, E. Technology \& Economic Development . London : Longman ,1997

MARSHALL, A. Principles of Economics . London : MacMillan and Co, 1920.

MILLAN, B., \& CONCHEIRO, A. Mexico 2030 : Nuevo Siglo, nuevo pais. Mexico : Fondo de Cultura ,2000

MONTANER ,C.A. Culture and the behavior of Elites in Latin America. In: Harrison ,L.E. (Ed.).
Culture Matters . New York: Basic Books, 2000, p 56-64.

ORGANIZATION FOR ECONOMIC CO-OPERATION AND DEVELOPMENT (OCDE). OECD statistical database. Disponivel em < http:// www.oecd.org $>$. Acesso em julho 2006.

PORTER, M. A Vantagem Competitiva das Nações. Rio de Janeiro : Campus, 1993

PORTER, M. ; STERN, S. Inovação e Localização de mãos dadas. HSM Management, Jan- Fev. 2002.

SAGASTI,F. Ciencia, Tecnologia y Desarollo Latinoamericano. Mexico: Fondo de Cultura,1981

SCHUMPETER, J. Capitalism, Socialism and Democracy. London: Allen \& Unwin , 1943

STIGLITZ , J. ; WALSH, C. Introdução à Microeconomia . Rio de Janeiro : Campus, 2003

Revistas e sites consultados para elaboração do ranking das maiores empresas:

América Economia - “As 500 maiores empresas da América Latina “ ,edição de 14 /7/ 2006.

Business Week - " The BusinessWeek Global 1200 “ ,edição de 26/12/2005

Forbes - “ 2000 Global “ , edição de 17 de abril de 2006.

Fortune - “Fortune Global 500 “ , edição de 24/7/2006

Latin Trade -site consultado em agosto de 2006 : www.latintrade.com

Artigo enviado em novembro de 2006

Artigo aceito em abril de 2007 
